\title{
Covid-19 y animales, ¿una oportunidad para la abolición de la esclavitud especista?
}

\author{
Brenda Yesenia Olalde Vázquez \\ Maestra en Derecho Procesal Constitucional \\ Universidad Michoacana de San Nicolás de Hidalgo \\ orcid.org/0000-0001-7727-9394
}

Cita recomendada. OLALDE VÁZQUEZ, B.Y., Covid-19 y animales, ¿una oportunidad para la abolición de la esclavitud especista? dA. Derecho Animal (Forum of Animal Law Studies) 11/4 (2020). - DOI https://doi.org/10.5565/rev/da.525

\section{Resumen}

La pandemia por SARS-COV-2, ha exigido al animal humano tomar acciones de salvaguarda, inclusive, lo ha llevado a reflexionar con mayor atención sobre su relación con los demás animales. Frente al panorama actual de contingencia, el ámbito jurídico debe prepararse para ampliar consideraciones de protección jurídica e iniciar el camino de la abolición de la esclavitud especista.

Palabras clave: Animales; Bienestar Animal; Constitución; Esclavitud; Especismo; Explotación; Derechos Animales; Derechos Fundamentales; Covid-19.

Abstract - Covid-19 and animals: an opportunity for the abolition of speciesist slavery?

The SARS-COV-2 pandemic has required the human animal to take safety measures, including leading to deeper reflection on its relationship with other animals. Faced with the current state of contingency, the law must prepare itself to broaden legal protection considerations and begin on the path towards the abolition of speciesist slavery.

Keywords: Animals; Animal Welfare; Constitution; Slavery; Speciesism; Exploitation; Animal Rights; Fundamental Rights; Covid-19. 


\section{Sumario}

1. Nota introductoria

2. De la violencia y esclavitud especista. Consideraciones conceptuales

3. Covid-19 y animales, ¿una oportunidad para la abolición de la esclavitud especista?

4. Consideraciones finales

5. Fuentes de consulta

\section{Nota introductoria}

El 11 de marzo de 2020, la Organización Mundial de la Salud (OMS), declaró la enfermedad provocada por el virus SARS-COV-2 como pandemia, hecho que exige cuestionar la forma en la que el animal humano interactúa con los demás animales y con la Naturaleza misma.

La preocupación del problema de la crueldad y violencia contra los animales no humanos no es reciente, sin embargo, ha cobrado especial atención, sobre todo ante la innegable crisis ambiental y la actual contingencia sanitaria.

Los procesos de desarrollo tecnológico e industrialización, pareciere que ha desconectado a la especie humana de su propia animalidad, anulando el valor moral que tienen sus cohabitantes, reduciéndolos jurídicamente a un estatus de cosas con el fin de oprimirles ensañadamente.

De la mano del antropocentrismo, el animal humano ha normalizado la violencia y esclavitud especista, cometiendo hasta ahora, prácticas abusivas y exterminadoras de los demás animales y de la Naturaleza en general.

En medio de la contingencia sanitaria, es necesario discutir sobre los entramados normativos de bienestar animal que legitiman prácticas especistas, como las leyes que regulan el sistema de consumo, dado que la crisis por el SARS-COV-2, se presume, es consecuencia de la compra-venta, sacrificio y consumo de animales "salvajes" o "silvestres". En este sentido, el bienestar animal, presenta síntomas de colapso, toda vez que se muestra como una estrategia fallida para el resguardo de la integridad y seguridad sanitaria de los animales no humanos e indirectamente de los animales humanos.

La enfermedad provocada por el SARS-COV-2, es una enfermedad zoonótica, que de acuerdo con la Organización Mundial de la Salud, son infecciones transmitidas de forma natural de los animales no humanos a los animales humanos, siendo el vehículo de transmisión la exposición directa o indirecta o mediante el consumo de productos de origen animal. ${ }^{1}$

Los mercados en los que se vende la carne o los subproductos de animales salvajes, advierte la Organización Mundial de la Salud, son peligrosos debido al gran número de patógenos nuevos y no documentados. $^{2}$

Por su parte, la Organización Mundial de Sanidad Animal señala que la información disponible sugiere que el SARS-CoV-2 es de origen animal, la pandemia se mantiene a través la transmisión de humano a humano y advierte que las infecciones pueden tener consecuencias para la salud humana y animal, el bienestar animal, la conservación de la fauna silvestre y la investigación biomédica. ${ }^{3}$

Es innegable, que cada año son asesinados millones de animales no humanos para uso de la especie humana, en prácticas especistas como la ganadería industrial, mismo que para Gary L. Francione, es una forma de esclavitud, en virtud del carácter de objeto de propiedad en el que están los animales no humanos.

El sistema cárnico, legitimado por el derecho, bajo directrices que parecen poco eficaces para el control sanitario, está generando consecuencias irreparables para todos los animales, humanos y no humanos, por lo que en este trabajo, se pretende analizar esta crisis sanitaria como una oportunidad para expandir las categorías

\footnotetext{
${ }^{1}$ Organización Mundial de la Salud (OMS). Página web URL: https://www.who.int/foodsafety/areas_work/zoonose/es/ [Última consulta en Agosto, 2020].

${ }^{2}$ Organización Mundial de la Salud (OMS). Página web URL: https://www.who.int/es/news-room/fact-sheets/detail/zoonoses [Última consulta en Agosto, 2020].

3 Organización Mundial de Sanidad Animal (OIE). Página web URL: https://www.oie.int/es/nuestra-experienciacientifica/informaciones-especificas-y-recomendaciones/preguntas-y-respuestas-del-nuevo-coronavirus-2019/ [Última consulta en Agosto, 2020].
} 
de protección constitucional y trazar caminos hacia la abolición de la esclavitud especista.

\section{De la violencia y esclavitud especista. Consideraciones conceptuales}

\subsection{Violencia especista}

El especismo es la forma de discriminación hacia quienes no pertenecen a determinada especie ${ }^{4}$, es decir, es el conjunto de conductas y/o actividades de menosprecio basado prejuicios por la diferencia de especie.

La práctica del especismo, en palabras de Romina Kachanoski, es violencia especista, un tipo de violencia que los humanos ejercen hacia los demás animales ${ }^{5}$. Kachanoski, quien acuñó este término, lo refiere como un "problema social emergente a escala planetaria que, lejos de prevenirse o erradicarse, se presenta como un recurso para actuar en sociedad". ${ }^{6}$

En la actualidad, la violencia especista, es una constante, ya que los animales no humanos, son discriminados por la diferencia de especie y violentados que reciben un trato de cosas o bienes de propiedad, lo que permite sean utilizados en prácticas crueles, excesivas y abusivas que no tienen justificación moral ni ética para continuar perpetuándolas, como la industria cárnica, la cual, tiene al borde del colapso sanitario no solo a la especie humana, sino al planeta mismo, que se ve rebasado en la problemática ambiental que ocasiona la ganadería industrial.

En la esfera del Derecho, para regular o intentar prevenir la crueldad que sufren los animales no humanos destinados para consumo, se ha buscado implementar estrategias de bienestar animal desde los años 60s del siglo pasado, las cuales se rigen, principalmente en premisas humanitarias y de buen trato.

Las necesidades actuales, de cara al control de la pandemia, debe llevar al animal humano a redefinir su relación con los demás animales, con el objeto incluso de recuperar una conciencia más empática con lo que rodea, así como interactuar de una forma más armónica y compasiva con sus cohabitantes, por lo que jurídicamente, un paso ineludible, es reconocer la violencia especista como un problema social, a fin de generar límites jurídicos de responsabilidad, prevención y erradicación.

Esta violencia, debe ser tipificada en bases normativas con el objeto de prevenir y sancionar el daño a los demás animales, con la finalidad de trazar jurídicamente caminos hacia su prohibición y erradicación. La violencia especista, entonces, podría entenderse como el abuso arbitrario ejercido a través de actos u omisiones que generan maltrato, crueldad o exterminio de los animales no humanos, sobre justificaciones discriminatorias de especie.

Para cerrar este apartado, no solo es necesario la codificación de la violencia especista, sino que también requiere que la especie humana abandone posiciones antropocéntricas, reconociendo el valor moral de los demás animales.

\subsection{De la esclavitud especista}

Por el devenir histórico de la humanidad, cuando se habla de esclavitud, pareciera entenderse a que nos estamos refiriendo, algunas definiciones jurídicas de esta figura, coinciden en la condición de un individuo considerado como cosa (esclavo) y sometido a la propiedad plena de otro que ejerce un rol de autoridad y dominio (amo).

La Convención sobre la Esclavitud del 25 de septiembre de $1926^{7}$, define la esclavitud como el estado o condición de un individuo sobre el cual se ejercitan los atributos del derecho de propiedad, a través de la captura, adquisición o cesión de individuos con carácter de esclavos ${ }^{8}$.

La especie humana, ostentándose como "dueño" de todo lo existente a su alrededor, desconectado de su propia animalidad, en la aparente búsqueda de una vida "más cómoda", "más urbana" y menos "salvaje" o "primitiva", en los sistemas jurídicos ha reducido a los demás animales como objetos de propiedad o cosas.

Con apoyo de posturas antropocéntricas se ha normalizado no solo a la violencia especista, sino a la misma esclavitud especista. La esclavitud especista o esclavitud animal, puede entenderse como el sistema en el que los animales no humanos, considerados como cosas de propiedad (esclavos) de animales humanos (amo

\footnotetext{
${ }^{4}$ Ética animal. Especismo. Sitio web. URL: https://www.animal-ethics.org/etica-animales-seccion/especismo/ [Última consulta en Agosto, 2020]

${ }^{5}$ Revista Latinoaméricana de Estudios Críticos Animales. Entrevista a Romina Kachanoski. Sitio web. URL: http://revistaleca.org/journal/index.php/RLECA/article/view/63 [Última consulta en Agosto, 2020].

${ }^{6}$ Ídem.

${ }^{7}$ Oficina del Alto Comisionado de las Naciones Unidas para los derechos humanos. La Abolición de la Esclavitud y sus Formas contemporáneas. Sitio web. URL: https://www.ohchr.org/documents/publications/slaverysp.pdf [Última consulta en Agosto, 2020] ${ }^{8}$ Idem. 
u opresor) y mediante la violencia y opresión, son condicionados a actividades de servidumbre.

En la esclavitud especista, sistema en el que alguien (un animal no humano) es oprimido por otro (animal humano), su opresor, el oprimido o esclavo es:

- Inferior o diferente al dueño;

- Una mercancía (que puede ser capturada, comprada o vendida);

- Dependiendo de sus características físicas, pueden ser empleado en actividades como jornadas excesivas de trabajo;

- Puede ser sacrificado.

El Dr. Gary Francione, sostiene que la regulación de la explotación animal es inmoral y condenada al fracaso porque el estatus de propiedad de los animales significa que los intereses de los animales nunca pueden prevalecer sobre los intereses de los dueños humanos, explica que la regulación de la explotación animal fracasa en los mismos términos de la regulación de la esclavitud humana. ${ }^{9}$

Francione sostiene una analogía entre los sistemas de explotación animal y la esclavitud humana. Él señala que si se afirma que los no humanos, a diferencia de los esclavos humanos, solo tienen interés en no sufrir, es una posición utilitarista, puesto que la cuestión moral no es el uso, sino el trato.

Francione argumenta que el paradigma de los derechos exige moralmente la abolición de la explotación animal y el veganismo como una cuestión de justicia fundamental, diferente del paradigma asistencialista, que, en teoría, se centra en la reducción del sufrimiento. ${ }^{10}$

En discordancia con lo que afirma Francione, no puede negarse la importancia de los criterios de bienestar animal, porque aunque no convergen con la aspiración de la liberación animal, ha sido posible incorporarlos en el ámbito jurídico como directrices necesarias para alejar de los malos tratos a los demás animales.

Efectivamente, las posiciones del bienestar animal, colapsan frente a la idea de los derechos de los animales, pero en el natural devenir del Derecho, el paso siguiente es reconfigurar el estatus de los demás animales, abriendo paso al reconocimiento de sus derechos e iniciar con el progresivo fin del esclavismo especista.

El desafío respecto de los derechos de los demás animales, implica la restructuración de lo considerado como parte de la comunidad social, jurídica y política, con el objeto de construir un orden jurídico equilibrado que opere en armonía entre los animales, humanos y no humanos y, la Naturaleza.

La ruta entonces es, en principio, la descosificación, dejar de considerar a los demás animales como "recursos", "objetos", "productos", "bienes" o "especímenes", para reconocerlos como individuos autónomos con aspiraciones tan legítimas como las "humanas", como el deseo de mantenerse libres de sufrimiento y conservar y disponer de su vida; y, en colectividad (todas las especies animales), el animal humano, debe reconocer que es el grupo vulnerable más agraviado de todos los tiempos, todo esto sistemáticamente para dar fin al trato de esclavos que da a los demás animales.

\section{Covid-19 y animales, ¿una oportunidad para la abolición de la esclavitud especista?}

De manera global, la mayoría de las legislaciones que buscan reducir o prevenir el maltrato y crueldad del que son víctimas los animales no humanos, son entramados en el que el estatus jurídico de los animales es de cosas, objetos de propiedad, instrumentos, recursos, especímenes, mercancías o productos, sin embargo, la exigencia social y jurídica actual, requiere de la reconfiguración jurídica de los animales no humanos, con la finalidad de reconocerles como sujetos de derechos, lo cual implicaría dejar atrás la esclavitud bajo la cual son oprimidos.

Las leyes actuales sobre el bienestar animal, en su mayoría, legitiman la violencia especista, al solapar prácticas como la pesca, la caza, vivisección, producción animal, entre otras, justificándose en razones culturales, económicas y de aprendizaje en las que los demás animales desempeñan el papel de esclavos.

El bienestar animal es entendido como el estado óptimo con el que deben contar los animales no humanos, en función del animal humano.

Para alcanzarse el bienestar animal, es necesario cumplir y proveer a los animales de las llamadas "Cinco libertades" "11, que de acuerdo a la Organización Mundial de Salud (OIE), son las siguientes:

\footnotetext{
9 Animal Rights: the abolitionist approach. Sitio web. URL: https:/www.abolitionistapproach.com/animal-rights-slaveryrapeanalogies/ [Última consulta en Agosto, 2020].

${ }^{10}$ Animal Rights: the abolitionist approach. Sitio web. URL: https://www.abolitionistapproach.com/animal-rights-animal-welfareand-the-slavery-analogy/ [Última consulta en Agosto, 2020].

${ }^{11}$ World organization for animal health (OIE). Página web URL: https://www.oie.int/en/animal-welfare/animal-welfare-at-a-glance/
} 
- Libertad de hambre, de sed y de desnutrición.

- Libertad de temor y de angustia.

- Libertad de molestias físicas y térmicas.

- Libertad de dolor, de lesión y de enfermedad.

- Libertad de manifestar un comportamiento natural.

Estos parámetros de bienestar animal, quedan lejos de alcanzarse en la realidad, toda vez que aunque son llamadas "libertades", no reducen la violencia especista, bajo estas "libertades", los no humanos, son esclavos, cosas susceptibles de propiedad.

El bienestar animal, no es del todo negativo, porque ha sido una estrategia que se implementó con el objeto de "reducir" las condiciones de maltrato y de crueldad que el animal humano ejerce contra de los demás animales, sin embargo, en la lucha por los derechos de los animales, las metas son el reconocimiento de la autonomía y libertad de los animales así como el abolicionismo de los sistemas de opresión animal.

Existen ordenamientos jurídicos, que han dado paso a incluir a los animales no humanos como seres vivientes y sensibles como el caso del Código Civil ${ }^{12}$ de Francia, incluso, hay Constituciones que han incorporado a sus bases fundamentales, disposiciones sobre los demás animales, sin embargo, carecen de una base epistémica y teórica, quedando en normas sin efectos de aplicación, como el caso de la Constitución de India, la de Alemania o la de Suiza. Lo mismo sucede en Latinoamérica, cuyos ordenamientos de protección y bienestar animal, no reconfiguran el estatus de los demás animales, ni mucho menos les reconocen libertades.

Para señalar las Constituciones a las que hacemos referencia, las mencionaremos a continuación, no sin antes advertir, que no acogen tampoco la protección animal como un principio constitucional, sino que por el contrario, incorporan a los animales no humanos como elementos-objetos que deben protegerse para alcanzar fines a futuro. Estas Constituciones son las siguientes:

- India.

Dentro de su Constitución de 1950, en el apartado VI, relativo a los deberes fundamentales, en su numeral $51^{\mathrm{a}}$, establece como un deber humano, la compasión por las criaturas vivientes:

\section{A. Fundamental duties. - It shall be the duty of every citizen of India-}

(g) to protect and improve the natural environment including forests, lakes, rivers and wild life, and to have compassion for living creatures, ${ }^{13}$

- Brasil

En su Constitución, en el numeral 225, ha establecido que para asegurar el derecho al ambiente equilibrado, es necesaria la protección de la fauna y flora, prohibiendo las prácticas que provoquen la extinción de especies o sometan a los animales a la crueldad:

Art. 225. Todos têm direito ao meio ambiente ecologicamente equilibrado, bem de uso comum do povo e essencial à sadia qualidade de vida, impondo-se ao Poder Público e à coletividade o dever de defendê-lo e preservá- lo para as presentes e futuras gerações:

...

VII - proteger a fauna e a flora, vedadas, na forma da lei, as práticas que coloquem em risco sua função ecológica, provoquem a extinção de espécies ou submetam os animais a crueldade. ${ }^{14}$

- Suiza.

En su texto fundamental en su numeral 120, considera la dignidad de las criaturas, en cuanto a la protección de la variedad genética de animales, plantas y otros organismos.

Art. 120 Gentechnologie im Ausserhumanbereich*

...

[Última consulta en Agosto, 2020].

${ }^{12}$ Code Civil, 2004. Francia. Texto vigente a agosto, 2020

${ }^{13}$ Constitution of India, 1950. Texto vigente a agosto, 2020.

${ }^{14}$ Constituição da República Federativa do Brasil, 1988. Texto vigente a agosto, 2020.

166 Derecho Animal. Forum of Animal Law Studies, vol. 11/4 


\section{Der Bund erlässt Vorschriften über den Umgang mit Keim- und Erbgut von Tieren, Pflanzen und anderen Organismen. Er trägt dabei der Würde der Kreatur sowie der Sicherheit von Mensch, Tier und Umwelt Rechnung und schützt die genetische Vielfalt der Tier- und Pflanzenarten. ${ }^{15}$}

- Alemania.

En 2002, en su Constitución, dispuso en su artículo 20 a, proteger los fundamentos naturales de la vida y los animales a través de la legislación:

Art 20 a:

Der staat schützt auch in verantwortung für die künftigen generationen die natürlichen lebensgrundlagen und die tiere im rahmen der verfassungsmäßigen ordnung durch die gesetzgebung und nach maßgabe von gesetz und recht durch die vollziehende gewalt und die rechtsprechung. ${ }^{16}$

Como se había advertido, ninguna de éstas constituciones reconoce a los demás animales como seres sintientes o sensibles, tampoco hablan de la protección animal como un principio constitucional, ni mucho menos, los reconoce con derechos fundamentales en sí mismos.

La preocupación actual, es buscar medidas de control de la pandemia de Covid-19, sin embargo, desde el Derecho, es posible también encontrar soluciones, no con el efecto quizá de erradicar la pandemia, pero sí estrategias que pueden funcionar en un sentido de prevención de futuras crisis epidémicas, apostando a nuevas consideraciones de protección jurídica, que promuevan la abolición de prácticas industriales que ponen en riesgo el futuro.

La pandemia por el SARS-COV-2, así como las contingencias sanitarias de los últimos tiempos como el MERS-COV o aquellas provocadas por el virus de la influenza H5N2 o el H1N1, se presume hasta ahora, son consecuencia de la desequilibrada relación que sostiene el animal humano con los demás animales. Esta contingencia, debe ser vista como una oportunidad para la especie humana para redefinir el modo de vida que pone en riesgo el futuro de la existencia tanto humana como la no humana, cuestionar la forma en que interactúa con los demás animales y prescindir de prácticas antropocéntricas y especistas que laceran y avasallan a sus cohabitantes y a la Naturaleza misma.

Desde el ámbito del Derecho, con el objeto de actualizar las categorías de protección jurídica, la pandemia puede significar una razón para atender las exigencias por la liberación animal. En este sentido, la esfera jurídica, entonces, debe prepararse para la transformación de un nuevo paradigma de los derechos, en el cual, el animal humano, con base en la perspectiva de la reivindicación de los animales, no figurará como opresor especista, sino como agente responsable de proteger y de evitar causar daño hacia la Naturaleza y demás animales, rigiéndose por principios de respeto, armonía y compasión.

Para establecer la ruta jurídica a seguir, que promueva la prevención de futuras catástrofes sanitarias, el primer paso, es aceptar que el bienestar animal como lineamiento jurídico, es una estrategia que actualmente, no logra cumplir con los objetivos de sanidad animal y que además, provoca consecuencias ambientales que repercuten en la salud humana, animal y de la propia Naturaleza.

Otro paso ineludible para prevenir futuras pandemias, es la reconfiguración del estatus jurídico de los animales no humanos, aboliendo la cosificación de los demás animales, ya que de esta manera, será posible iniciar el camino de la reconfiguración de la propiedad de los animales, la cual, como figura jurídica, es un obstáculo para el reconocimiento como sujetos de derechos.

Es claro, que con relación a los animales no humanos, no son los únicos puntos que deben atenderse desde el Derecho, puesto que uno de los objetivos concretos de la lucha por la reivindicación animal, es la propia liberación animal, que podría materializarse a través de libertades que permitan transformar el estatus de opresión en el que están regidos para ser considerados como integrantes de la comunidad jurídica.

Para poder hablar de la constitucionalización de derechos animales, es necesario la consideración de los no humanos como sujetos de derechos, reconociendo que son seres sintientes, merecedores de respeto y trato digno, lo cual es clave para transitar a un orden jurídico en el que la crueldad, la injusticia, la violencia y el maltrato animal, sean impensables e inoperantes. Un orden jurídico que contribuya a la construcción de una sociedad armónica y pacífica que permita, cohabitar y coexistir a los animales humanos y no humanos. Esta constitucionalización, requiere de valores como la no violencia, con el objeto de establecer desde la base jurídica, el respeto de la vida de todos los animales, humanos y no humanos, así como de la Naturaleza misma y lo que a ella integre, acompañado de responsabilidad y cuidado colectivo.

Entonces hasta aquí tenemos que, la pandemia actual por el virus SARS-COV-2, puede ser una

\footnotetext{
${ }^{15}$ Bundesverfassung der Schweizerischen Eidgenossenschaft, 1999. Texto vigente a agosto, 2020.

${ }^{16}$ Grundgesetz für die Bundesrepublik Deutschland, 1949. Texto vigente a agosto, 2020
} 
justificación para delimitar desde el Derecho, prácticas excesivas, crueles y abusivas que perpetúan la opresión de millones de animales, con el objeto de trazar caminos hacia la erradicación de la violencia especista y la abolición de la esclavitud especista, reconociendo el valor inherente e intrínseco de los animales no humanos, como individuos, dueños de su propia vida, autónomos y libres, a partir del respeto de su dignidad, dejando atrás la esclavitud, la opresión, el abuso y el daño del cual, han estado y hasta ahora, están sometidos.

Los derechos de los animales, se buscan como normas jurídicas que reconociendo la sintiencia y dignidad intrínseca de los animales no humanos, tienen el objetivo de procurar, proteger, promover y salvaguardar su libertad, su integridad y su vida (derecho a la vida, derecho a la integridad física y mental, derecho a la protección, derecho a la libertad). Estos derechos son prerrogativas a favor de los demás animales, con el propósito de protegerlos y salvaguardar sus intereses, a través de delimitar el comportamiento y la interacción que tiene el animal no humano con ellos.

Además, de reconocer derechos para los animales no humanos, es necesario que se establezcan deberes o responsabilidades para el animal humano, sin extinguir la conexión natural entre ellos, porque incluso reconocer derechos a las demás especies, es parte de fortalecer la propia consciencia sobre la animalidad del animal humano. También es importante señalar que, reconocer a los animales no humanos como sujetos de derechos, no debe quedarse en la mera declaración normativa, sino por el contrario, debe traducirse en estrategias que permitan la interacción entre el animal humano con los demás animales y con la Naturaleza de una manera más armónica y menos arbitraria ni invasiva. Estas estrategias pueden ser, entre otras:

- Fomentar la consciencia colectiva -humana- compasiva, pacífica e incluyente de los demás animales;

- Difusión del valor intrínseco de las vida de los demás animales y la naturaleza, a través de políticas públicas y planes nacionales, reconociéndolos como fines en sí mismos y no como medios o recursos;

- Incorporar en los planes y gestiones gubernamentales la protección de los derechos de los animales no humanos;

- Promover la abolición de prácticas crueles con animales, así como la transformación de los modelos de explotación animal como parte de una estrategia de prevención de crisis sanitarias y el colapso de la salud del planeta;

- De manera internacional, los Estados- Nación, deben ya atender la crueldad, la violencia y la esclavitud especista, como un problema que debe erradicarse, acordando parámetros que reconozcan como parte de las agendas legislativas y gubernamentales la protección de los demás animales.

Es posible que sea necesario considerar como valores para alcanzar las acciones anteriores, lo siguiente:

- El respeto de los seres vivientes (animales -humanos y no humanos, y de la Naturaleza en sí misma)

- Cuidado empático y compasivo de todo lo que integra al planeta.

También será necesario, deconstruir las premisas antropocéntricas y de violencia especista legitimadas por el Derecho, para la construcción de una comunidad animal humana más responsable, compasiva y armónica con los demás animales y con la Naturaleza.

El Derecho puede jugar un papel importante para regular la conducta que tenemos con la Naturaleza y con los demás animales y, en el caso de futuras pandemias prevenirlas a través de la prohibición y erradicación de prácticas especistas. En lo que respecta a la abolición de la esclavitud especista, cabe advertir, que constitucionalizar derechos, no es la panacea al problema, pero puede ayudar a la transformación de las consideraciones éticas, jurídicas, políticas y sociales que tiene el animal humano respecto de los demás animales, al reconfigurar su estatus jurídico y reconocer sus derechos.

La especie humana, no debe ver ajena la lucha de los derechos de los animales, por el contrario, debe ajustarse a consideraciones más justas y compasivas con sus cohabitantes, regirse por directrices éticas y morales que le permitan conducirse con respeto a todos los seres vivientes, ser más consciente de su propia animalidad y del papel que ocupa en el desarrollo de la vida y, que en conjunto, es decir, toda la especie humana, se constituya como una colectividad a la que le sea impensable la crueldad, la injusticia y la violencia, permitiendo un desarrollo más sano del planeta.

\section{Consideraciones finales}

La consideración de los animales no humanos como parte de nuestra comunidad, no es una discusión nueva por la estrecha relación que el ser humano mantiene con los no humanos, sin embargo, esta relación ha 
sido ejercida de manera violenta y aventajada por parte de la especie humana. La actual emergencia sanitaria por el virus SARS-COV-2, obliga a cuestionar sobre los efectos de la "normalidad" antropocéntrica, que nos ha llevado a esta crisis y es que, acciones humanas tan comunes, como tomar un vaso de leche o consumir una porción de carne, impacta negativamente tanto en la Naturaleza, como en los propios animales -humanos y no humanos.

Aunque la atención sobre el COVID-19, se centra en la búsqueda de soluciones científicas inmediatas, es claro que también deben buscarse respuestas desde el ámbito jurídico, observar y analizar, de qué manera el derecho puede abonar a dar soluciones. Entre las causas que dieron lugar a la pandemia por SARS-COV-2, se presume, ha sido por el consumo de animales silvestres, que aunque aún no está comprobado, debe obligar a repensar las consideraciones jurídicas de los demás animales, la falta de regulación sobre el tráfico de especies, la legitimidad de la industria cárnica excesiva, la deficiencia de las directrices de bienestar animal, la cacería, el entretenimiento, compra-venta y sacrificio de animales, entre otros.

La esclavitud especista, sostenida por el antropocentrismo, mantiene el dominio de animal humano, sobre los otros animales, sin embargo, no puede seguir siendo admitido o aceptado tal sistema, pues el humano, abusando de esta condición ha violentado, oprimido y masacrado sin control a los animales no humanos, trayendo consecuencias irreparables, es por ello, que esta crisis, puede ser vista como una oportunidad para dar inicio de la abolición de la esclavitud especista.

El espectro jurídico, debe evolucionar y prestar atención a la necesidad de redefinir la forma en que el animal humano interactúa con los demás animales, y el Derecho puede delimitar esta relación a través de la reconfiguración de las categorías de sujetos de derecho, la actualización del estatus jurídico de los animales y el fortalecimiento de las leyes que normalizan y legitiman la violencia y la esclavitud especista.

El ascenso desmedido de la violencia especista, nos ha llevado a consecuencias tan graves, como lo es el actual estado de crisis sanitaria. La crisis por el Covid-19, nos ha permitido prestar atención no solo a la relación con los demás animales, sino también, reflexionar sobre la interconexión e interdependencia que tenemos con ellos y con la Naturaleza misma.

La violencia y la explotación animal ha sido una constante en la historia de la humanidad, en los últimos años hemos sido testigos del aumento excesivo de dicha violencia y de las consecuencias que el antropocentrismo ha provocado, de ahí, la urgencia de redefinir la manera en la que interactuamos con los demás animales.

Nos encontramos justo frente a la oportunidad de reivindicar a los animales no humanos, transitar de la explotación animal al reconocimiento de sus derechos. Cuando hago referencia sobre la oportunidad de abolición de la esclavitud especista, no me refiero a limitar la relación entre humanos y no humanos, sino a la imperante necesidad de cambiar el paradigma jurídico de su estatus y sobre todo, a la necesidad de construir bases jurídicas y epistémicas sólidas, que permitan traducirse en acciones que permitan respetar toda forma de vida, con el objeto de reducir las consecuencias antropocéntricas, dando esperanza a alcanzar un futuro más justo y menos cruel, un futuro, en el que sea inaceptable la violencia.

Aprovechar este momento para asumir y adoptar nuevas formas de consideración de los animales, fortaleciendo la idea de una consideración más ética, integrando jurídica, política y socialmente a los demás animales. Transitar del antropocentrismo al antiespecismo, siendo conscientes que la esclavitud no se regula, se prohíbe, es decir, aprovechar la oportunidad de reconocer los derechos de los animales no humanos, progresivamente dando paso a la abolición de la esclavitud especista.

Finalmente es necesario insistir en la importancia de la reconfiguración del estatus de los demás animales así como del reconocimiento de sus derechos, porque es un necesario acto de justicia, el cual debe atenderse ya; apostar a la eliminación de las prácticas cruentas que no contribuyen al fortalecimiento de la cultura de la paz, ni mucho menos a la compasión y armonía entre los animales y con la Naturaleza. Esta crisis sanitaria, debe servir para reflexionar y cuestionar la relación humano-no humano, afín de generar un espacio jurídico, político y social incluyente de los animales no humanos, recordando que la esclavitud no se regula, se prohíbe, de ahí, la urgencia de aprovechar la contingencia sanitaria como una oportunidad progresiva de la abolición de la esclavitud especista.

\section{Fuentes de consulta}

\section{Legislativas:}

- Bundesverfassung der Schweizerischen Eidgenossenschaft, 1999. Texto vigente a agosto, 2020.

- Code Civil, 2004. Francia. Texto vigente a agosto, 2020

- Constituição da República Federativa do Brasil, 1988. Texto vigente a agosto, 2020.

- Constitution of India, 1950. Texto vigente a agosto, 2020. 
- Grundgesetz für die Bundesrepublik Deutschland, 1949. Texto vigente a agosto, 2020

\section{Electrónicas:}

- Animal Rights: the abolitionist approach. Sitio web. URL: https://www.abolitionistapproach.com/animal-rights-slaveryrape-analogies/ [Última consulta en Agosto, 2020].

- Animal Rights: the abolitionist approach. Sitio web. URL: https://www.abolitionistapproach.com/animal-rights-animal-welfare-and-the-slavery-analogy/ [Última consulta en Agosto, 2020].

- Ética animal. Especismo. Sitio web. URL: https://www.animal-ethics.org/etica-animalesseccion/especismo/ [Última consulta en Agosto, 2020]

- Oficina del Alto Comisionado de las Naciones Unidas para los derechos humanos. La Abolición de la Esclavitud y sus Formas contemporáneas. Sitio web. URL: https://www.ohchr.org/documents/publications/slaverysp.pdf [Última consulta en Agosto, 2020]

- Organización Mundial de la Salud (OMS). Página web URL: https://www.who.int/foodsafety/areas_work/zoonose/es/ [Última consulta en Agosto, 2020].

- Organización Mundial de la Salud (OMS). Página web URL: https://www.who.int/es/newsroom/fact-sheets/detail/zoonoses [Última consulta en Agosto, 2020].

- Organización Mundial de Sanidad Animal (OIE). Página web URL: https://www.oie.int/es/nuestraexperiencia-cientifica/informaciones-especificas-y-recomendaciones/preguntas-y-respuestas-delnuevo-coronavirus-2019/ [Última consulta en Agosto, 2020].

- Revista Latinoaméricana de Estudios Críticos Animales. Entrevista a Romina Kachanoski. Sitio web. URL: http://revistaleca.org/journal/index.php/RLECA/article/view/63 [Última consulta en Agosto, 2020].

- World organization for animal health (OIE). Página web URL: https://www.oie.int/en/animalwelfare/animal-welfare-at-a-glance/ [Última consulta en Agosto, 2020]. 